\title{
PREVALENCE, RISK FACTORS AND OUTCOMES OF PREGNANCIES WITH SMALL FOR GESTATIONAL AGE FETUS AT BPKIHS
}

\author{
Shrestha $R^{1^{*}}$, Bhandari $S^{1}$, Basnet $P^{2}$, Manandhar $T^{1}$, Thapa $B D^{1}$, Shrestha $S^{3}$, Kafle $S P^{4}$
}

\begin{abstract}
Affiliation
1. Assistant Professor, Obstetrics and Gynaecology, B. P. Koirala Institute of Health Sciences, Dharan, Nepal

2. Additional Professor, Obstetrics and Gynaecology, B. P. Koirala Institute of Health Sciences, Dharan, Nepal

3. Master in Nursing, Women's Health and Development, Institute of Medicine, Maharajgunj Nursing campus, Kathmandu, Nepal

4. Assistant Professor, Pediatrics, B. P. Koirala Institute of Health Sciences, Dharan, Nepal
\end{abstract}

\section{ARTICLE INFO}

Received : 21 October, 2019

Accepted : 17 January, 2020

Published : 30 June, 2020

(C) Authors retain copyright and grant the journal right of first publication with the work simultaneously licensed under Creative Commons Attribution License CC - BY 4.0 that allows others to share the work with an acknowledgment of the work's authorship and initial publication in this journal.

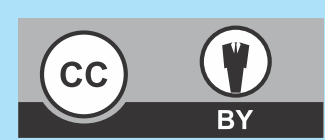

ORA 155

DOI: https://doi.org/10.3126/bjhs.v5i1.29612

\section{* Corresponding Author}

Dr. Ramesh Shrestha

Assistant Professor

Obstetrics and Gynaecology

B. P. Koirala Institute of Health Science, Dharan, Nepal Email: stharamesh007@gmail.com

ORCID ID: https://orcid.org/0000-0001-7947-859X

\section{Citation}

Shrestha R, Bhandari S, Basnet P, Manandhar T, Thapa BD, Shrestha S, Kafle SP. Prevalence, Risk Factors and Outcomes of Pregnancies with Small for Gestational Age Fetus at BPKIHS. BJHS 2020;5(1)11: 911-915.

\section{ABSTRACT \\ Introduction}

Small-for-gestational-age (SGA) is defined by a birth weight below the $10^{\text {th }}$ percentile for mean weight corrected for gestational age. It is associated with adverse health events throughout life, including substantial perinatal morbidity and mortality rates.

\section{Objectives}

The aims of the study was to assess the prevalence, attributable factors and perinatal outcomes of SGA.

\section{Methodology:}

A prospective cohort study was conducted in Department of Obstetrics/Gynaecology, BPKIHS from October, 2016 to June, 2017among 150 singleton pregnant women after 28 weeks' gestation whose symphysio-fundal height lags the gestational age by four cms. The association between the risk factors and SGA was analysed using chi-square test for categorical and t-Test for continuous data. The mothers and babies were followed up till discharge from the hospital for outcomes.

\section{Results}

There was a total of 140 SGA among 6,500 hospital deliveries, hence the prevalence was $2.15 \%$. The risk factors for very SGA were history of birth of SGA fetus (OR, 1.25; 95\% Cl, 1.15-1.35); recurrent pregnancy loss (OR, 1.25; $95 \% \mathrm{Cl}, 1.15$ $1.35)$; substances abuse in the index pregnancy (OR, 1.68; $95 \% \mathrm{Cl}, 1.47-1.92)$; adverse obstetrics or medical events in the index pregnancy $(\mathrm{OR}, 2.21 ; 95 \% \mathrm{Cl}, 1.10-4.45)$; high blood pressure at admission (OR, 1.58; 95\% Cl, 1.96-2.59) and significant proteinuria $(\mathrm{OR}, 2.26 ; 95 \% \mathrm{Cl}, 1.00-5.09)$. SGA babies correlated with increased operative delivery, oligohydramnios, low Apgar scores and neonatal resuscitation at birth, NICU or nursery admission, neonatal metabolic complications and fetal death.

\section{Conclusions}

SGA have distinct modifiable risk factors and mortality patterns suggesting potential implications for public health and urgent need to intervene with effective interventions

\section{KEYWORDS}

Outcomes, prevalence, riskfactors, small for gestational age. 


\section{INTRODUCTION}

Birth weight, a function of both gestational age and fetal growth, is the most important determinant of a newborn infant's chances to survive and grow in health. In the 1940s clinicians became aware that low birth weight did not necessarily signify an infant born preterm, but may also be caused by fetal growth insult. In 1967, Lubchenko and Battaglia introduced the terms small-for-gestational age (SGA), appropriate-for-gestational age (AGA) and large-forgestational age (LGA). ${ }^{1}$ SGA is defined by birth weight below the $10^{\text {th }}$ percentile for their gestational age. The classification of neonates by birth weight percentile has a significant prognostic advantage because it improves the detection of neonates with growth insult who are at increased risk for adverse health events throughout life. ${ }^{1.4}$ Newborn babies are now classified as very small for gestational age or severe small for gestational age(below the $3^{\text {rd }}$ percentile), small for gestational age(below the $10^{\text {th }}$ percentile) and appropriate for gestational age $\left(10^{\text {th }}-90^{\text {th }}\right.$ percentile).$^{5}$ Of all fetuses less than $10^{\text {th }}$ percentile growth, approximately $40 \%$ are at high risk of preventable prenatal death, $40 \%$ are healthy small, and $20 \%$ are naturally small due to chromosomal or environmental insults. ${ }^{6}$ On average, one third of newborns with low weight at birth are reported to experience SGA. Growth potential percentiles are superior to conventional reference ranges for the prediction of adverse perinatal outcome. ${ }^{7,8}$

The cause of SGA is multifactorial, and comprised of maternal, placental, fetal or environmental factors. Approximately two-thirds of the SGA fetuses are related to intrauterine environment. However, no underlying etiology can be identified in $30-40 \%$ of SGA fetuses. SGA is associated with substantial perinatal morbidity and mortality rates like fetal demise, birth asphyxia, meconium aspiration, neonatal hypoglycemia, polycythemia, hyperviscosity, hypothermia, abnormal neurological development etc. The present study aimed to identify risk factors, prevalence and perinatal outcomes in small for gestational fetuses and thus help to improve the prognosis of infants by preventing the modifiable risk factors or early diagnosis and treatment of nonmodifiable risk factors and through intensive perinatal management.

\section{METHODOLOGY}

This was a hospital based prospective study carried out in the Department of Obstetrics and Gynaecology, BPKIHS, Dharan from October, 2016 to June, 2017. All singleton pregnancies after 28 weeks' gestation with cephalic presentation, confirmed gestational age (sure of last menstrual period with regular cycles or dating scan), symphysio-fundal height lagging the gestational age by four $\mathrm{cms}$ (suspected small for gestational age) and admitted in antenatal ward for safe confinement were included in the study. Pregnancies not sure of their last menstrual date and without dating scan or before 28 weeks' gestation or clinically oligohydramnios or abnormal lie and not giving consent were excluded from the study. According to Barati et. al. ${ }^{9}$ the prevalence of SGA fetus was $10.6 \%$. Considering $10.0 \%$ as the prevalence of SGA fetus, $95 \%$ Confidence interval, $80 \%$ power, 5\% permissible error and $10 \%$ non responders and measurement bias; thefinal sample size calculated using the following formula $\left(n=Z^{2} p q / d^{2}\right)$ was 150 . Ethical clearance was obtained from the Hospital Institutional Review Board prior to start the study.

Non-probability sampling (Purposive sampling) method was used to enroll the pregnant women fulfilling the inclusion and exclusion criteria during the study period. Patients or her attendants were enquired about the detailed history of complicating risk factors as per the proforma after admission in antenatal ward. They were managed as per the hospital management protocol for plan of investigations, treatments and delivery. Mothers and babies were followed up after delivery in the maternal and neonatal ward till discharge for outcomes. Data analysis was done using SPSS version 23.0; SPSS, Chicago, IL, USA. Frequency with percentage was used to describe categorical data and mean with Standard deviation and median with interquartile range was used to describe continuous data. The association for risk factors between the various socio-demographic parameters and SGA was analysed using chi-square test for categorical data and $t$-Test for continuous data with $\mathrm{p}$ value $<0.05$ considered as significant. Odds ratio at $95 \%$ confidence interval was used to predict the degree of association between SGA and risk factors.

\section{RESULTS}

During the study period, there were 140 SGA and 10 AGA new borns among 150 study population and 6500 total hospital deliveries above 28 weeks' gestation, hence the prevalence of SGA was $2.15 \%$. The mean estimated fetal weight on sonography at admission was $1.840 .46 \mathrm{~kg}$. The mean birth weight of newborns was $1.780 .43 \mathrm{~kg}$.

The median age of the pregnant women in the study was 25.03 years (IQR=22.41-28.35). The median gestational age at delivery was 37.5 weeks (IQR=36.0-39.0). The median duration of hospital stay of the pregnant women after admission till discharge was 4 days (IQR=3.0-6.0) [Figure 1].

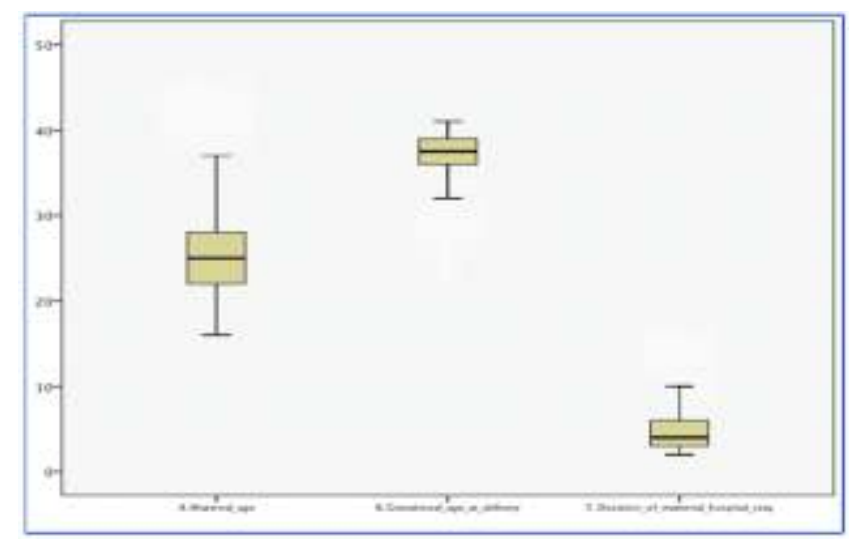

Figure 1. Box and whisker plot showing median maternal age in years, gestational age at delivery in weeks and duration of hospital stay in days (+IQR/Range). 
Most of the pregnant women ( $n=134 ; 89.3 \%$ ) were of $20-34$ age group.About three-fifth of the pregnant women were unbooked $(n=89 ; 59.3 \%)$, nulliparous $(n=90 ; 60.0 \%)$ and had oligohydramnios ( $n=92 ; 61.4 \%$ ) and less than four antenatal care (ANC) visits ( $n=87 ; 58.3 \%)$. About half of the pregnant patients were hypertensive at admission ( $n=69 ; 46.0 \%)$ [Table no.1].

About two-third of the pregnant women had delivery by caesarean section $(n=93 ; 62.0 \%)$ and the most common indication was non reassuring non stress test $(n=42 ; 28.0 \%)$. $41.3 \%(n=62)$ of the pregnant women had preterm deliveries. Only $10 \%(n=15)$ of them had post-partum complications and postpartum hemorrhage $(n=10 ; 6.7 \%)$ was the commonest [Table no. 2].

140 out of 150 babies (93.3\%) delivered were small for gestational age $\left(<10^{\text {th }}\right.$ percentile) and $121(80.7 \%)$ were very small for gestational age $\left(<3^{\text {rd }}\right.$ percentile). Most of the newborns $(n=124 ; 82.7 \%)$ had five minutes Apgar score 7. $17.3 \%(n=26)$ of the newborns had five minutes Apgar score $<7$ among which $7.3 \%$ (11) had Apgar score 0 (10 were intrauterine fetal death and1 was still birth). Similarly, 13 (8.7\%) newborns had expired within seven days of life (Early neonatal death) [Table no. 3].

Among the various socio-demographic characteristics, the significant risk factors for very SGA babies (Less than $3^{\text {rd }}$ percentile babies versus more than or equal to $3^{\text {rd }}$ percentile babies) were history of birth of SGA fetus (OR, 1.25; 95\% Cl, 1.15-1.35); history of recurrent pregnancy loss (OR, 1.25; $95 \% \mathrm{Cl}, 1.15-1.35)$; personal history of substances use in the index pregnancy $(\mathrm{OR}, 1.68 ; 95 \% \mathrm{Cl}, 1.47-1.92)$; adverse obstetrics or medical events in the index pregnancy (OR, 2.21; $95 \% \mathrm{Cl}, 1.10-4.45)$; high blood pressure at admission (OR, 1.58; $95 \% \mathrm{Cl}, 1.96-2.59)$ and significant urinary proteinuria on dipstick test (OR, 2.26; $95 \% \mathrm{Cl}, 1.00-5.09)$ [Table no. 4].

\begin{tabular}{|c|c|c|}
\hline Socio-demographic characte ristics & Frequencies & Percentage \\
\hline \multicolumn{3}{|l|}{ Age in years } \\
\hline$<20$ & 11 & 7.4 \\
\hline $20-34$ & 134 & 89.3 \\
\hline$\geq 35$ & 5 & 3.3 \\
\hline \multicolumn{3}{|l|}{ Types of visits } \\
\hline Unbooked & 89 & 59.3 \\
\hline Booked & 61 & 40.7 \\
\hline \multicolumn{3}{|l|}{ Number of antenatal visits } \\
\hline$<4$ & 87 & 58.0 \\
\hline$\geq 4$ & 63 & 42.0 \\
\hline \multicolumn{3}{|l|}{ Types of conception } \\
\hline Induced & 7 & 4.7 \\
\hline Spontaneous & 143 & 95.3 \\
\hline \multicolumn{3}{|l|}{ Uterine malformations or myomas } \\
\hline Absent & 150 & 100.0 \\
\hline \multicolumn{3}{|l|}{ Parity } \\
\hline Nullipara & 90 & 60.0 \\
\hline Primipara & 46 & 30.6 \\
\hline Multipara & 14 & 9.3 \\
\hline \multicolumn{3}{|l|}{ History of birth of SGA fetus } \\
\hline $\begin{array}{l}\text { Yes } \\
\text { None }\end{array}$ & $\begin{array}{r}4 \\
146\end{array}$ & $\begin{array}{r}2.7 \\
97.3\end{array}$ \\
\hline
\end{tabular}

\begin{tabular}{|c|c|c|}
\hline \multicolumn{3}{|l|}{ History of recurrent pregnancy loss } \\
\hline Yes & 4 & 2.7 \\
\hline None & 146 & 97.3 \\
\hline \multicolumn{3}{|l|}{ Index pregnancy birth spacing in years } \\
\hline 0 & 90 & 60.0 \\
\hline$<2$ & 11 & 7.3 \\
\hline$\geq 2$ & 49 & 32.7 \\
\hline \multicolumn{3}{|l|}{$\begin{array}{l}\text { Personal history of substances use in the index } \\
\text { pregnancy }\end{array}$} \\
\hline Smoker/alcoholic & 8 & 5.4 \\
\hline None & 142 & 94.6 \\
\hline \multicolumn{3}{|l|}{$\begin{array}{l}\text { Medical comorbidities ( Chronic HTN or Overt } \\
\text { DM or PMTCT) }\end{array}$} \\
\hline Yes & 9 & 6.0 \\
\hline None & 141 & 94.0 \\
\hline \multicolumn{3}{|l|}{$\begin{array}{l}\text { Adverse obstetrics or medical events in the index } \\
\text { pregnancy }\end{array}$} \\
\hline Hyperemesis gravidarum or Threatened abortion & 3 & 2.0 \\
\hline $\begin{array}{l}\text { Moderate-severe anemia or Hypothyroidism or } \\
\text { overt DM }\end{array}$ & 13 & 8.7 \\
\hline Preeclampsia or Chronic APH & 35 & 23.4 \\
\hline Mixed & 8 & 5.4 \\
\hline None & 91 & 60.7 \\
\hline \multicolumn{3}{|l|}{ Blood pressure } \\
\hline Hypertensive & 69 & 46.0 \\
\hline Normotensive & 81 & 54.0 \\
\hline \multicolumn{3}{|l|}{ HELLP syndrome } \\
\hline Present & 16 & 10.7 \\
\hline Absent & 134 & 89.3 \\
\hline \multicolumn{3}{|l|}{ Urinary proteinuria on dipstick test } \\
\hline Significant proteinuria $(\geq 2+)$ & 37 & 24.7 \\
\hline Mild proteinuria (1+) & 5 & 3.3 \\
\hline Normal-trace proteinuria $(<1+)$ & 108 & 72.0 \\
\hline \multicolumn{3}{|l|}{ Amniotic fluid volume } \\
\hline Severe oligohydramnios $(\mathrm{AFI}<5 \mathrm{~cm})$ & 28 & 18.7 \\
\hline Borderline oligohydramnios $(\mathrm{AFI}=5-8 \mathrm{~cm})$ & 64 & 42.7 \\
\hline Normal (AFI>8 cm) & 58 & 38.6 \\
\hline
\end{tabular}

\section{Table 2: Maternal outcomes ( $n=150)$.}

Parameters

Frequency Percentage

\section{Gestational age at delivery}

$\begin{array}{lll}<37 \text { weeks } & 62 & 41.3 \\ 37-40 \text { weeks } & 72 & 48.0 \\ >40 \text { weeks } & 16 & 10.7\end{array}$

\begin{tabular}{lcc}
\hline Modes of delivery & & \\
Spontaneous vaginal delivery & 22 & 14.7 \\
Induced vaginal delivery & 35 & 23.3 \\
Caesarean section & 93 & 62.0 \\
\hline Indication of caesarean section & & \\
Non reassuring NST & 42 & 28.0 \\
Previous cesarean section & 11 & 7.3 \\
Failed induction & 7 & 4.7 \\
PMTCT & 2 & 1.3 \\
Others & 31 & 20.7 \\
\hline Postpartum complications & & \\
Postpartum hemorrhage & 10 & 6.7 \\
Sepsis & 3 & 2.0 \\
Postpartum eclampsia & 2 & 1.3 \\
\hline
\end{tabular}

NST=Non-stress test; PMTCT=Prevention of mother to child transmission 


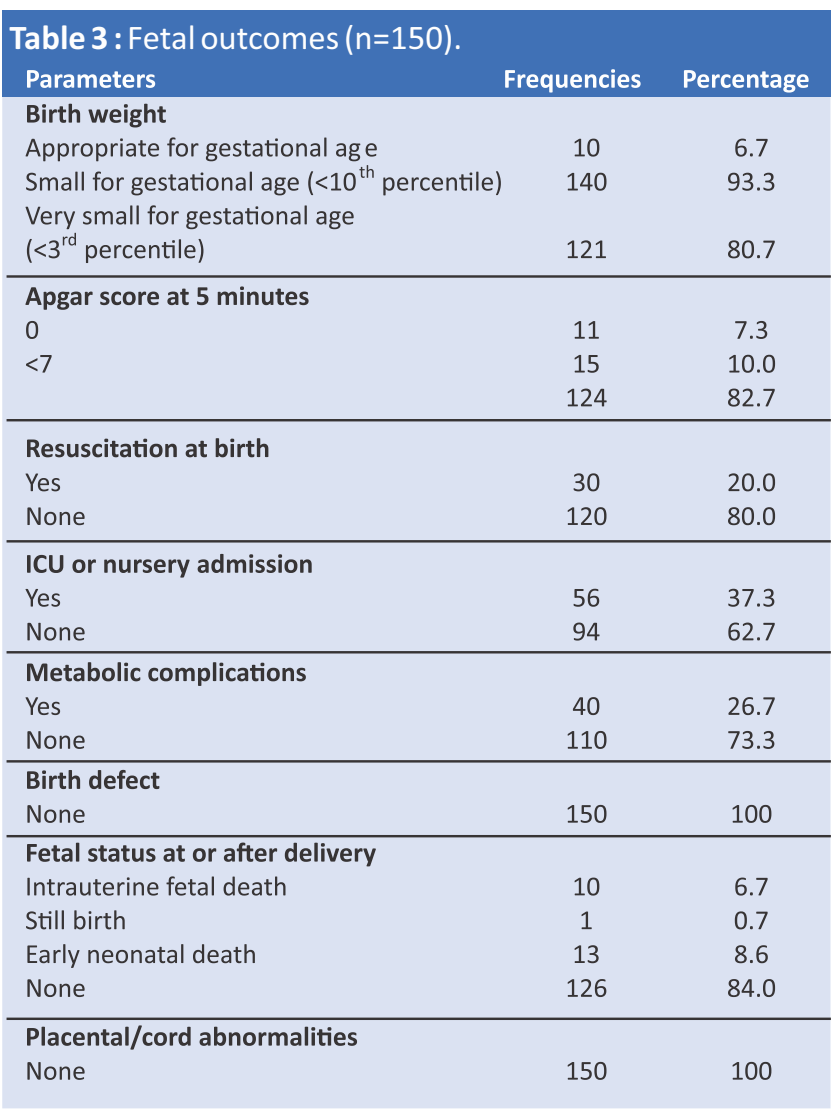

$\mathrm{ICU}=$ Intensive care unit

\begin{tabular}{llc}
$\begin{array}{l}\text { Table 4: Risk factors for very small for gestational age (<3rd } \\
\text { percentile babies; } n=121) .\end{array}$ & \multicolumn{1}{l}{ OR (CI) } & P value \\
$\begin{array}{l}\text { Socio-demographic character istics } \\
\text { Age in years (<20 vs } \geq 20 \text { ) }\end{array}$ & $1.81(0.33-4.22)$ & 0.53 \\
\hline Types of visits (Unbooked vs booked) & $1.18(0.60-2.29)$ & 0.38 \\
\hline Number of ANC visits (<4 vs $\geq 4)$ & $0.91(0.47-1.76)$ & 0.46 \\
\hline Parity (Nullipara vs $\geq 1$ para) & $1.88(0.97-3.65)$ & 0.61 \\
\hline History of birth of SGA fetus (Yes vs none) & $1.25(1.15-1.35)$ & 0.04 \\
\hline History of recurrent pregnancy loss (Yes vs none) & $1.25(1.15-1.35)$ & 0.04 \\
\hline Birth intervals in years (<2 vs $\geq 2)$ & $1.47(0.693 .14)$ & 0.20 \\
\hline $\begin{array}{l}\text { Personal history of substances abuse in the index } \\
\text { pregnancy (Yes vs none) }\end{array}$ & $1.68(1.47-1.92)$ & 0.03 \\
\hline Medical comorbidities (Yes vs none) & $2.45(0.4912 .20)$ & \\
\hline Adverse events in the index pregnancy (Yes vs none) & $2.21(1.104 .45)$ & 0.03 \\
\hline $\begin{array}{lll}\text { Blood pressure (Hypertensive vs normotensive) } \\
1.58(1.962 .59)\end{array}$ & 0.04 \\
\hline HELLP syndrome(Yes vs none) & $0.69(0.20-2.31)$ & 0.51 \\
\hline Urinary proteinuria on dipstick test ( $\geq 2+$ vs $\leq 1+)$ & $2.26(1.00-5.09)$ & 0.03 \\
\hline Microvascular disease (Yes vs none) & $2.03(0.2020 .03)$ & 0.47 \\
\hline
\end{tabular}

$\mathrm{ANC}=$ Antenatal care; $\mathrm{SGA}=\mathrm{Small}$ for gestational age; $\mathrm{HELLP}=$ Hemolysis, elevated liver enzymes, low platelet count; $\mathrm{OR}=$ Odds ratio; $\mathrm{Cl}=$ Confidence interval.

\section{DISCUSSION}

Small for gestational age (SGA) refers to infants whose weight is less than the average range for infants of the same gestational age. Small for gestational age (SGA) is not only a major indicator of perinatal mortality and morbidity, but also the morbidity risks later in life. The etiology of SGA is very heterogeneous. Few studies have tried to study risk factors for small for gestational age.
In the Secondary Data Analyses of the WHO Multi-Country Survey conducted across 29 countries by Ota E et. al. ${ }^{10}$, the overall prevalence of SGA was highest in Cambodia (18.8\%) followed by Nepal (17.9\%) while the lowest was observed in Afghanistan (4.8\%). Also most of these pregnant women delivering SGA babies were of 20-34 years age group, nullipara, had vaginal delivery and with newborns having Apgar score at 5 minutes 7. Similar results were found in our study with respect to age groups, parity and Apgar score at 5 minutes but in contrast the prevalence of SGA newborns was $2.15 \%$ and the commonest mode of delivery was caesarean section in our study. Also, the risk of SGA infants was significantly higher among women with preeclampsia/ eclampsia, anaemia and other medical conditions which is in consistent to our study.

In a retrospective study done among 341 pregnant women by Barati M et. al. ${ }^{9}$, the prevalence of SGA and severe SGA fetuses was $10.6 \%$ and $2.6 \%$ respectively of all cases and SGA deliveries was more common among nullipara. Similar results were observed in our study with prevalence of severe SGA being $1.86 \%$ of all deliveries and most of the mothers with SGA delivery being nulliparous (60\%).

In a double-blind cluster-randomized community trial in rural Sarlahi District Nepal, among 4130 pregnant women by Kozuki N et. al. ${ }^{11}$, majority of the pre-term (76.0\%) and term SGA (79.0\%) were of $18-35$ age groups which is comparable to our study.

A case control study done among 200 newborns by Hameed $\mathrm{NN}$ et. al. ${ }^{12}$ showed that there was significant relationship between SGA infants and antepartum hemorrhage, mother not attended antenatal care, maternal history of SGA births, mother with anemia and hypertension which is in consistent with the results of our study.

A retrospective study done among 3046 babies by Nakamura M et. al. ${ }^{13}$ showed the significant causal relationship of SGA newborns with the following maternal and fetal risk factors like multiple pregnancy, fetal malformations, pregnancy induced hypertension and low body mass index(<18.5). Similar significant causal relationship of SGA newborns was observed in our study with respect to hypertension complicating pregnancy.

A retrospective cohort study done among 49,945 women by Hung TH et. al. ${ }^{14}$ showed that the significant risk factors for idiopathic SGA newborns were hypercoiling of the umbilical cord, prior fetal death, primiparity, adolescent pregnancy, low prepregnancy weight, low prepregnancy body mass index, short stature and entangled umbilical cord. SGA newborns correlated with increased risk of adverse perinatal outcomes including fetal death, low Apgar scores, oligohydramnios, placental abruption, and admission to the neonatal intensive care unit. This is in consistent with the findings of our study in which the significant risk factors for SGA were history of birth of SGA fetus, history of recurrent pregnancy loss, personal history of substances use in the current pregnancy, adverse events in the current pregnancy, hypertension complicating pregnancy and significant proteinuria. 
The possible outcomes, prevalence and risk factors observed in this study thus mimic reported trend in Eastern Nepal and as a whole of Nepal too. Possible modifiable risk factors observed in our study for SGA could be minimized or patients with non-modifiable risk factors could be advised for preconceptional counselling and treatment.

\section{CONCLUSIONS}

Our results demonstrate that SGA is a common perinatal health concern with causal association with conditions like birth of SGA babies, recurrent pregnancy loss, adverse obstetric events, substances abuse during pregnancy and medical conditions related to pre- eclampsia or eclampsia and urinary proteinuria. Increased risk of ICU admission, need of resuscitation at birth, metabolic complications, perinatal death and operative delivery were also higher among SGA babies.

\section{RECOMMENDATION}

Though the sample size was comparatively small, this result clearly identified that global prevention for SGA should mainly focus on these modifiable and non-modifiable risk factors. Because of the increased perinatal morbidity and mortality risk associated with SGA, it is a public health issue with an urgent need to act in joints with effective interventions.

\section{Strength and limitation of the study}

The strength of our study was that it was a prospective cohort study. BPKIHS, Dharan is a the tertiary health care centre in the Eastern part of Nepal. Most of the pregnancies with suspected SGA from eastern region of Nepal are referred here, hence it reflects the problem of eastern region of Nepal. This study had certain limitations. It was a single hospital based study with comparatively small sample, so considering the community based study or multicentered study with larger sample size would better reflect the actual scenario of this perinatal health issue so as to observe the possible risk factors, prevalence and outcomes.

\section{ACKNOWLEDGEMENT}

I would like to thank Dr. Sangeeta Bhandari for her help in data collection, my wife Mrs. Sapana Shrestha for her help in statistical analysis and those pregnant women who had consented for this study; without them this study wouldn't have been possible.

\section{CONFLICT OF INTEREST}

None declared

\section{FINANCIAL DISCLOSURE}

None.

\section{REFERENCES}

1. Battaglia FC, Lubchenco LO. A practical classification of newborn infants by weight and gestational age. J Pediatr. 1967 Aug;71:15963.PMID: 6029463. DOI: 10.1016/s0022-3476(67)80066-0

2. Lubchenco LO, Hansman C, Dressler M, Boyd E. Intrauterine growth as estimated from liveborn birth-weight data at 24 to 42 weeks of gestation. Pediatrics.1963 Nov;32:793-800.PMID: 14075621.

3. Barker DJ. Fetal growth and adult disease. Br J Obstet Gynaecol. 1992 Apr;99(4):275-PMID: 1581269. DOI: 10.1111/j.1471-0528.1992 .tb13719.x

4. Bernstein IM, Horbar JD, Badger GJ, Ohlsson A, Golan A. Morbidity and mortality among very-low-birth-weight neonates with intrauterine growth restriction: The Vermont Oxford Network. Am J Obstet Gynecol. 2000 Jan;182(1 Pt 1):198-206.PMID: 10649179. DOI: 10.1016/s0002-9378(00)70513-8

5. Hoffman HJ, Stark CR, Lundin FE, Ashbrook JD. Analysis of birth weight, gestational age, and fetal viability, U.S. births, 1968. Obstet Gynecol Surv.1974 Sep;29(9):651-81.PMID: 4427722. DOI: 10.1097/ 00006254-197409000-00029

6. Manning FA, Hohler C: Intrauterine growth retardation: diagnosis, prognostication, and management based on ultrasound methods. In Fleischer AC, Romero R, Manning FA, et al (eds): The Principles and Practices of Ultrasonography in Obstetrics and Gynaecology, 11th ed. Norwalk, CT, Appleton and Lange. 2019, p 331.

7. Bukowski R, Burgett AD, Gei A, Saade GR, Hankins GD. Impairment of fetal growth potential and neonatal encephalopathy. Am J Obstet Gynecol. 2003 Apr;188(4):1011-5.PMID: 12712102. DOI: $10.1067 / \mathrm{mob} .2003 .233$

8. Clausson B, Gardosi J, Francis A, Cnattingius S. Perinatal outcome in SGA births defined by customised versus population-based birthweight standards. Br J Obstet Gynaecol. 2001 Aug;108(8):830-4. PMID: 11510708. DOI: 10.1111/j.1471-0528.2001.00205.x
9. Barati M, Moramezi F, Moramezi H, Shizadi N, Shizadi P. Evaluating the prevalence of small for gestational age and its associated risk factors. Jentashapir J Health Res. 2016 June; 7(3):e36171. doi:10.17795/jjhr.36171.

10. Ota E, Ganchimeg T, Morisaki N, Vogel JP, Pileggi C, et al. Risk Factors and Adverse Perinatal Outcomes among Term and Preterm Infants Born Small-for-Gestational-Age: Secondary Analyses of the WHO Multi-Country Survey on Maternal and Newborn Health. PLOS ONE. 2014;9 (8): e105155. doi:10.1371/journal. pone.0105155.PMID: 25119107. DOI: 10.1371/journal.pone.0105155

11. Kozuki N, Katz J, LeClerq SC, Khatry SK, West KP Jr, Christian P. Risk factors and neonatal/infant mortality risk of small-for-gestationalage and preterm birth in rural Nepal. J Matern Fetal Neonatal Med. 2015 Jun;28(9):1019-25.PMID: 25000447. DOI: 10.3109/14767058. 2014.941799

12. Hameed, N.N., Alzubaidi, M.A., Kadhim, S.H. 2011. Risk Factors of Small for Gestational Age Newborn Babies. The Iraqi Postgraduate Medical Journal. 2011;10(1):54-60.

13. Nakamura M, Hasegawa J, Matsuaka R, Mimura T, Ichizuka K, Sekizawa A, Okai T. Risk Analysis For The Birth Of A Small For Gestational Age (SGA) Infants. The Internet Journal of Gynecology and Obstetrics. 2009;13(2):1-5.

14. Hung TH, Hsieh TT, Lo LM, Chiu TH, Hsieh CH, Hsu JJ. Risk factors and perinatal outcomes associated with idiopathic small for gestational age Taiwanese newborns. Int J Obstet Gynaecol. 2013 Sep;122(3): 183-276.PMID: 23796255. DOI: 10.1016/j.ijgo.2013.03.033 